Goldschmidt 2021 Abstract

https://doi.org/10.7185/gold2021.7830

\section{Redox dynamics of atmospheric mercury at Maido Observatory in the tropical Indian Ocean}

ALKUIN MAXIMILIAN KOENIG ${ }^{1}$, OLIVIER MAGAND ${ }^{2}$, JÉRÔME BRIOUDE ${ }^{3}$, AURÉLIE COLOMB ${ }^{4}$, FRANÇOISE VIMEUX $^{5}$, MICHEL RAMONET ${ }^{6}$, RAINER VOLKAMER ${ }^{7}$, JULIE REGIS $^{2}$, ALBAN BELLOIR ${ }^{2}$, JEAN-MARC METZGER $^{8}$, JEAN-PIERRE CAMMAS $^{3}$, JEROEN E SONKE $^{9}$ AND AURÉLIEN DOMMERGUE ${ }^{2}$

${ }^{1}$ Université grenoble Alpes - IGE

${ }^{2}$ Université Grenoble Alpes

${ }^{3}$ Lacy Laboratoire de l'Atmosphère et des Cyclones

${ }^{4}$ LaMP - Laboratoire de Météorologie Physique

${ }^{5}$ IRD/HSM-LSCE

${ }^{6}$ Laboratoire des Sciences du Climat et de l'Environnement, LSCE-IPSL

${ }^{7}$ University of Colorado at Boulder

${ }^{8}$ University of La Réunion - Observatory of Atmospheric Physics of La Réunion (OPAR)

${ }^{9} \mathrm{CNRS} /$ Université de Toulouse

Presenting Author: alkuin-maximilian.koenig@univ-grenoblealpes.fr

To fill important data gaps on atmospheric mercury in the Southern Hemisphere and to address uncertainties in mercury redox dynamics, we measured GEM during a nearly one-yearlong field campaign (from August 2017 to June 2018) at Maido Observatory on La Réunion island, located at an altitude of 2154 masl on the slope of an inactive volcano. During most of the measurement campaign, auxiliary information on $\mathrm{CO}_{2}, \mathrm{CH}_{4}, \mathrm{CO}$, $\mathrm{O}_{3}, \mathrm{SO}_{2}$, radon, water isotopes, and meteorological variables is also available. Located about $680 \mathrm{~km}$ east of Madagascar, La Réunion island is dominated by easterly trade winds and thus mostly exposed to air masses of marine origin, with limited seasonal variability in air mass transport. With a standard deviation (SD) of $0.05 \mathrm{ng} / \mathrm{m}^{3}$ for monthly averages, GEM concentrations showed little seasonal variation around the overall mean of $0.85 \mathrm{ng} / \mathrm{m}^{3}$ (SD for hourly data: $0.12 \mathrm{ng} / \mathrm{m}^{3}$ ), and the only notable feature of the seasonal cycle were moderately enhanced GEM concentrations during the Southern Hemisphere biomass burning season (mean of $0.93 \mathrm{ng} / \mathrm{m}^{3}$, SD: 0.11 ; during October - November). Diel GEM cycles at Maido exhibited a remarkable regularity, with higher GEM concentrations during daytime $\left(0.88 \mathrm{ng} / \mathrm{m}^{3}\right.$, SD: 0.11 ; between $6 \mathrm{AM}$ and $\left.8 \mathrm{PM}\right)$, when the observatory tends to be under the influence of the marine boundary layer (MBL), and lower GEM concentrations during nighttime $\left(0.81 \mathrm{ng} / \mathrm{m}^{3}\right.$, SD: 0.12 ; between $8 \mathrm{PM}$ and $\left.6 \mathrm{AM}\right)$, when a mix of free-tropospheric and boundary layer air can be sampled. However, during cyclonic storms, this diel variation diminished and the diel cycle flattened, probably due to a less pronounced vertical stratification in the lower troposphere and the expansion of the MBL. With the goal of exploring local sources and sinks, as well as redox dynamics of atmospheric mercury at this marine site, we group diel cycles into qualitatively different types, compare their behavior to that of auxiliary variables, and investigate the conditions leading to their appearance. We furthermore present one GEM depletion event which was clearly linked to an eruption of the islands' sporadically active volcano.

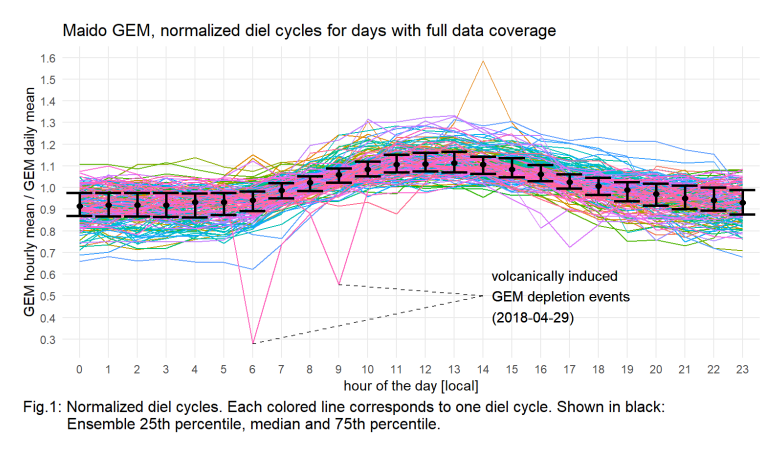

